\title{
How Much Does National Culture Constrain Organizational Culture?
}

\author{
Barry Gerhart \\ University of Wisconsin-Madison, USA
}

ABSTRACT The assumption of strategy approaches like the resource based view is that, despite environmental constraints, ample room remains for organizations to differentiate on the basis of organizational culture (together with related human resource practices) to achieve sustained competitive advantage. In contrast, other perspectives assume that management practice and organizational culture mirror, or are constrained by, national culture. To the degree that such a constraint exists, within-country variance in culture should be small and between-country variance large. In statistical terms, the first question is: what is the magnitude of the effect size for country? 'The larger the effect, the more likely it is a constraint. Second, what portion of the country effect size is due to differences in national culture? My review finds that most of the variance in organizational cultures is not explained by country; of the variance that is explained by country, only a minority is duc to national culture differences. As such, there may be more room for organizational differentiation than typically recognized. Third, under what circumstances will country and national culture effects be larger or smaller? I present a model suggesting more room for differentiation in countries having greater individual level variance in cultural values and related variables.

KEYWORDS cross-cultural studies, culture, human resource management, organizational behaviour, strategic management

\section{INTRODUCTION}

Organizations that operate in multiple countries must decide how much to localize their organizational culture and related management practices to fit within the host country context and how much to, instead, strive to maintain consistency or standardization (Bartlett \& Ghoshal, 1989; Perlmutter, 1969; Rosenzweig \& Nohria, 1994). The environment for organizations can differ across countries in a variety of dimensions, including regulations, institutions, centrality of markets, collective bargaining, labour force characteristics and culture. To the degree that country differences are significant and impose constraints on what organizations can and cannot do, one would expect greater localization. Empirically, this would 
translate into significantly greater between-country variance than within-country variance when observing organizations.

Hofstede (1983: 88) claimed that management is 'culturally dependent' and that 'if we see what effective organizations in different cultures have done, we recognize that their leaders did adapt foreign management ideas to local cultures'. Although he (Hofstede, 2001: 441-442) recognizes that 'there have been examples of multinationals successfully reforming local cultural traits', he cautions that 'this is a difficult task', and 'for best results a multinational's management practices should fit the local culture'.

The emphasis on the central role of national culture has continued in recent years. For example, the most recent large scale project, GLOBE (House, Hanges, Javidan, Dorfman, \& Gupta, 2004; Javidan, House, Dorfman, Gupta, Hanges, \& de Luque, 2004), while not explicitly using the term 'constraint', emphasizes that the relationship between national culture and organizational culture is strong with organizations mirroring the countries where they are found, which seems consistent with the idea of a constraint.

Johns (2006: 396) states explicitly that 'national culture constrains variation in organizational cultures'. His argument relies significantly on empirical work by Hofstede $(1980,2001)$ and on the work by Chatman and Jehn (1994), the latter who concluded that industry explained a substantial portion of the variance in organizational culture. Accordingly, Johns argues that 'the contextual imperative suggested by these findings stands in sharp contrast to the common view that cultures are shaped essentially through internal processes' (2006: 396).

There are, however, several issues with these conclusions. First, Gerhart and Fang (2005), in their re-analysis of Hofstede's data, show that country differences explain only a small percentage of the variance in individual level cultural values, suggesting that mean differences between countries are small relative to differences (i.e., variance) within countries. This considerable within-country variance at the individual level would be expected to contribute to variance in organizational cultures. Second, Gerhart (2008), in his re-analysis of Chatman and Jehn's (1994) data collected in the USA, shows that organizational differences, in fact, explained more variance in cultural values than did industry differences. This re-analysis casts doubt on the argument that organizational differences in culture are as constrained as is believed. Additional evidence shows considerable variation in organizational culture and strategies within other countries such as China (Krug \& Hendrischke, 2008; Tsui, Wang, \& Xin, 2006), suggesting room for managerial discretion. Third, no empirical research to date actually provides a direct estimate of the magnitude of the relationship between national culture and organizational culture. Conclusions about national culture as a constraint on organizational culture would be more compelling with such evidence.

Finally, from a conceptual point of view, Johns's (2006) conclusion that constraints such as national culture are a 'contextual imperative' which constrains 
internal management discretion stands in sharp contrast to frameworks in the strategy literature such as the resource based view (RBV) (Barney, 1986, 1991) and related human resources (HR) management perspectives (e.g., Barney \& Wright, 1998) that organizational culture (together with related HR practices) is a factor that organizations can use to create value and to differentiate themselves.

I propose that it would be useful to have a conceptual model that explains when national culture is most likely to be a constraint. In addition, I argue that a re-examination of empirical evidence is necessary. Although, as of yet, such evidence is indirect and in need of further analysis, it is central to the question of how much national culture and organizational culture 'mirror' each other and, thus, to the question: to what degree does national culture likely act as a key factor in the 'contextual imperative' described by Johns (2006)? I focus on these issues in the present paper.

\section{CONCEPTUAL ANALYSIS}

Johns (2006: 396) defines constraint in terms of restricted range or variance: 'one of the most basic things that context can do is affect the range of organization variables'. In a similar vein, Nelson and Gopalan (2003: 1122) argue that 'If variance within national samples is much smaller than between countries ... there is some indication that organizational cultures are subject to the constraints of the dominant [national] cultural environment'. Further, if so, 'intra-country variance in organizational culture [may be] so small as to present barriers to the diffusion of strong parent-company cultures' (1122).

The degree to which within-country variance in culture is restricted relative to between-country variance is a question of statistical effect size magnitude (e.g., Cohen, 1994) for country. Thus, I examine evidence on the country effect size, as well as the degree to which (overall) country effects are explained (specifically) by national culture effects. Because national culture is just one characteristic on which countries vary, the country effect is an upper bound for the national culture effect (Raudenbush \& Bryk, 2002: 74). I begin by placing the national culture as a constraint argument within the broader management literature and its differing perspectives on the relative importance of constraints and management discretion and strategy.

\section{Gonstraints and Strategic Choice}

In considering the claim that organizations are constrained by (or mirror) the national culture of the country where they are located, it is helpful to further clarify how the issue of constraint (versus management discretion) has been viewed in the broader management literature. Management theory recognizes that organizations face pressures to be similar to other organizations as well as opportunities to 
be different from other organizations. Institutional theory (DiMaggio \& Powell, 1983; Scott, 2000), for example, emphasizes that organizations respond or adapt to pressures in their environments to conform to accepted ways of doing business so that they will appear legitimate to investors, customers and others who can influence their success. Over time, institutional influences, whether industry specific or country specific, are expected to create a significant degree of similarity (or conformity) in structures and practices across organizations. Similarly, industrialorganizational economics perspectives de-emphasize firm differences in financial performance, instead focusing on the importance of industry differences in shaping and constraining strategies and performance (Bain, 1959; Porter, 1980).

The process common to these perspectives is that the environment constrains firm agency or discretion, which is observed as reduced variance in firm practices or attributes. In the short run, firms that do not conform are expected to have poorer performances, thus putting their survival at risk over the longer term as the environment selects firms that match the environment's demands (Hannan \& Freeman, 1977). To the degree that nonconforming firms do, in fact, more often fail, a further reduction in variance is observed.

In contrast, the resource based view (RBV) has taken the lead in 'reemphasizing the importance of organizations in strategy research' (Hoopes, Madsen, \& Walker, 2003: 889). The RBV focuses on how organizations differentiate themselves by 'looking inside' for resources and capabilities that are rare and difficult to imitate (and not substitutable) and that can be leveraged to build sustained competitive advantage (Barney, 1986, 1991; Carmeli \& Tishler, 2004; Wernerfelt, 1984). Thus, the RBV, in comparison to institutional and industrial-organizational economics theories, leads us to expect greater variance in firm practices and attributes. In addition, while sharing the view that being different (industry comparisons are often emphasized) can be risky, it also recognizes the opportunity to achieve sustained competitive advantage by not conforming to environmental pressures and constraints.

One resource that is a strong candidate for meeting the test of adding value and being difficult to imitate is organizational culture (Barney, 1986). Business press and academic studies on what makes some organizations perform better than others in the same industry often highlight the role of culture or related concepts such as ideology or values in making organizations distinctive, successful and difficult to imitate (e.g., Collins, 2001; Deal \& Kennedy, 1982; Denison, 1990; Kotter \& Heskett, 1992; Peters \& Waterman, 1982). According to Barney (1986: 664), 'precisely because an organization's culture is hard to describe ... and because even if the culture can be described, it is difficult to change; a firm's culture can hold promise for sustained superior financial performance for some firms.'

A primary avenue for firms to influence culture is through their human resource practices and strategies (Barney \& Wright, 1998; Den Hartog \& Verburg, 2004; 
Lado \& Wilson, 1994). Barney and Wright (1998: 43), for example, observe that 'one important implication of the [RBV] framework is that the Human Resource function manages the set of resources (e.g., human capital skills, employee commitment, culture, teamwork, etc.) that are most likely to be sources of sustained competitive advantage'. Lawler (2003: 35) states that 'the organizational design elements of people, structure, rewards, and processes lead to...corporate culture. ${ }^{\text {[1] }}$

Like the broader strategy literature and the RBV in particular, the literature on strategic human resources (e.g., Barney \& Wright, 1998; Becker \& Gerhart, 1996; Cappelli \& Crocker-Hefter, 1996; see also the strategic choice industrial relations framework, Kochan, Katz, \& McKersie, 1994) has proceeded under the assumption that organizations, even when facing similar competitive environments and pressures, can and do differentiate themselves with respect to human resource management practices and organizational cultures and that being unique may help generate uniquely high levels of success. Cappelli and Crocker-Hefter observe that 'there are examples in virtually every industry of highly successful firms that have very distinct management practices' (1996: 7).

Oliver (1991) has attempted to integrate strategic and institutional frameworks, as well as consider when and to what degree institutional pressure is most likely to act as an influence or constraint on strategy. She notes that 'the institutional perspective has been increasingly criticized for its lack of attention to the role of organizational self-interests and active agency' (145). She proposes that institutional theory 'can accommodate interest-seeking, active organizational behavior' if organizational responses are 'not assumed to be invariably passive and conforming to all institutional conditions' (146). She also describes five different strategic responses (acquiescence, compromise, avoidance, defiance, manipulation) and proposes that the type of strategic response depends on the nature of institutional pressures.

Of particular relevance here is Oliver's proposition that 'The lower the degree of economic gain perceived to be attainable from conformity to institutional pressures, the greater the likelihood of organizational resistance to institutional pressures' (1991: 161). Also of interest are her propositions that resistance is greater when institutional norms conflict with organizational goals and when there is a multiplicity of institutional constituents. Taken together, these suggest that conformity is resisted when being different is the organization's path to sustained competitive advantage, consistent with the RBV, and also that conformity is resisted when there is a lack of consensus among actors (i.e., multiplicity) in the institutional environment.

To summarize the discussion so far, there are different, perhaps conflicting, views in the broader management literature on the issue of constraint versus strategic choice and differentiation. The assumption made by the RBV and related frameworks (e.g., strategic human resources) is that organizations can differentiate themselves with respect to attributes like organizational culture (and related 
management practices). In contrast, institutional and industrial-organization economics views tend to give greater weight to the constraining influence of the environmental/institutional context. The organizational culture literature includes both perspectives. Finally, some work (e.g., Oliver, 1991) is aimed at understanding when constraints are most and least likely to limit managerial discretion.

\section{The Role of Intracountry Cultural Variability: A Conceptual Model}

In considering national culture as a constraint, I suggest that Oliver's (1991) concept of multiplicity relates to the concept of variance, an important theme in explanations of when national culture is most likely to act as a constraint. Limited within-country variance in norms (e.g., cultural values) may, in turn, act to limit the degree to which organizational cultures could be unique, whereas greater withincountry variance may provide organizations with more leeway to be unique. As discussed, this question concerns the effect size of country.

Au (1999: 806), in his discussion of intracultural variability, observed that multinational corporations (MNCs) 'usually have special preference for workers that suit their needs and company culture ... A heterogeneous [national] culture means a better chance for MNCs to achieve their goals, as the variety of labour within this culture can be as large as the MNC can find across a number of cultures'. Bloom and Milkovich (1999) argued that such variability would allow organizations to be more selective in their employee attraction, selection and attrition/retention (ASA) (Schneider, 1987) processes, thus making it more likely that an MNC could find the individual employees needed to serve as the foundation for its desired organizational cultures, even if it was not typical for that country.

Likewise, Tsui, Nifadkar and Ou (2007: 461) suggest that 'There is potential for interesting theory development by focusing on the variance of culture held by the individuals in a nation', using, for example, the concept of tightness or looseness of culture (Pelto, 1968; Triandis, 1989; cited in Tsui et al., 2007). Gelfand, Nishii and Raver (2006: 1226) define tightness-looseness in terms of 'The strength of social norms, or how clear and pervasive norms are within societies, and the strength of sanctioning, or how much tolerance there is for deviance from norms within societies.' In countries that have looser cultures, there should be more room for organizations to be distinctive and to find employees that fit that distinctive model. ${ }^{[2]}$

The model presented in Figure 1 summarizes the key ideas discussed thus far. The model shows that countries have different contexts and these contextual factors influence organizational culture and related management (especially human resources) practices. The model recognizes that culture is one of the ways that contexts differ across countries. Thus, some portion of the effect of country on organizational culture and related management practices is thought to be mediated by the country's cultural values. These, in turn, have two dimensions. First, the mean of individual cultural values is the traditional definition (and measure) of 
Figure 1. Country, national culture and organizational culture

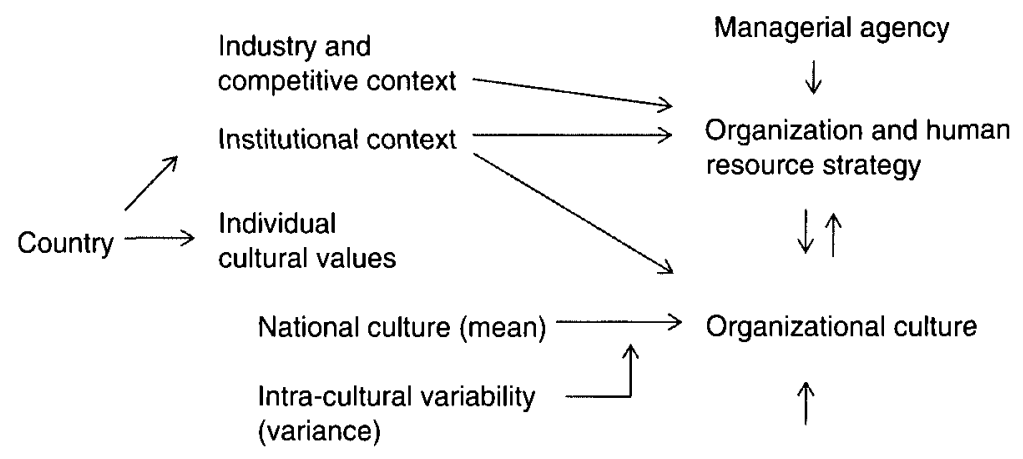

Organizational history

national culture. (Additional individual characteristics such as personality may also be relevant.)

Second, individual cultural values and other characteristics may vary more or less within some countries than in others. This intracultural variability (Au, 1999), which relates to the concept of cultural tightness-looseness, may statistically moderate the degree to which national culture influences organizational culture and related management practices. This statistical interaction would provide the most direct test of the constraint hypothesis. However, the Hofstede and GLOBE studies do not report within-country variance by country. Thus, the interaction cannot be tested as of yet using these data.

It is possible to estimate the magnitude of the average relationship between country and organizational culture and between the mean of cultural values (national culture) and organizational culture. To the degree that these effect sizes are large, on average, then organizational culture is more likely to be constrained. In contrast, smaller effect sizes (e.g., less variance explained) would argue, on average, against such a constraining influence. Gerhart and Fang's (2005) re-analysis of Hofstede's (1980) data as well as other research (Au, 1999; Oyserman, Coon, \& Kemmelmeier, 2002) suggests that there is considerable withincountry variation at the individual level in cultural values. To the degree this individual level variation translates into organization level variation within countries, the effect size of country (and national culture) on organizational culture would be weakened (Gerhart, 2008).

Note that the model in Figure 1 recognizes that, in addition to culture, countries differ in other aspects of their institutional environments and this broader institutional environment, as well as the competitive environment (e.g., industry, which also varies in terms of its institutional forces), management practices/strategy, organizational history and managerial agency, are expected to influence organizational culture. 
Before examining empirical evidence on the relationship between country, national culture and organizational culture and its implications for the constraint hypothesis, it is necessary to first define the meaning of a significant effect size, culture and the difference between country and culture.

\section{Defining Terms: Significance, Culture, and National Culture Effect}

What is a 'significant' effect size?' Country, as a constraint on organizational culture, would be expected, on average, to reduce variance within countries, relative to the variance between countries (Au, 1999; Johns, 2006; Nelson \& Gopalan, 2003). In other words, we can examine the degree to which the effect size for country (and a specific country characteristic such as national culture) on organizational culture is significant. ${ }^{[3]}$

The term 'significant' is used in the management literature in one of two ways. First, it is used to refer to statistical significance, where the focus is typically on whether or not a parameter (e.g., a mean, a regression coefficient) is different from zero. However, as noted by Kerlinger (1973: 227), 'tests of statistical significance like $t$ and $F$ unfortunately do not reveal ... the magnitude or the strength of the relations.' Thus, a second way to define 'significant' is in terms of practical significance, which relies on estimating some effect size indicator (Cohen, 1994; Schmidt, 1996). ${ }^{\left[{ }^{4]}\right]}$ Most studies of country differences, especially older studies, do not report effect sizes. Rather, they focus on statistical significance. Further, some studies have (incorrectly) sought to use the $F$ statistic as a measure of effect size. Both of these are issues in Hofstede's (1980, 2001) influential work (Gerhart \& Fang, 2005).

Because the dependent variables in culture research are not ratio variables, standardized (or 'scale free') measures of effect sizes, such as variance explained, are typically most useful. Measures include $r^{2}$ or, with a categorical independent variable (e.g., country), $\eta^{2}, \omega^{2}$, or the intraclass correlation (ICG) (Shrout \& Fleiss, 1979).

Cohen (1988) has suggested benchmarks for characterizing the magnitude of effect size. For $r$, and by implication, $r^{2}$ (and other variance explained indexes), these are:

$\begin{array}{cccc} & \text { Small } & \text { Medium } & \text { Large } \\ r & 0.10 & 0.30 & 0.50 \\ r^{2} & 0.01 & 0.09 & 0.25\end{array}$

How is culture defined? Schein (1992) has defined organizational culture as 'a pattern of shared basic assumptions' (12) that are 'stable and difficult to change' (21) and difficult to observe because 'many important parts of culture are essentially invisible' (21). Martin (2002: 56), after considering 12 different definitions of organizational culture, concluded that there were two areas of (relative) commonality: 
culture is 'shared' and 'is distinctive or unique to a particular context'. The 'shared' aspect suggests limited within-organization variance, while the 'distinctive or unique' part suggests significant between-organization variance.

Hofstede (1980) has defined national culture as the 'collective programming of the mind'. His focus was on cultural values, which he defined as a 'broad tendency to prefer certain states of affairs over others' (19). Hofstede saw cultural values as 'an attribute of individuals as well as of collectivities' though he stated that 'culture presupposes a collectivity' (19). Thus, Hofstede's definition of national culture also includes the shared aspect and, likewise, implies that within-country variance (where values are shared) should be considerably less than between-country variance (given 'broad tendency' differences).

Culture, whether national or organizational, can be conceptualized and measured at different levels of observability (e.g., practices, values, fundamental assumptions; Hofstede, 1980; Schein, 1992; Trompenaars \& Hampden-Turner, 2000). ${ }^{[5]}$ Cultural values are typically measured using questions that ask for an evaluation, preference, or value ('should be'), whereas cultural practices are measured using descriptive ('what is') questions of (perceived) fact. For example, a cultural values question might ask 'do you believe employees in this (organization or country) should be paid on the basis of individual performance?' whereas a cultural practices question might ask 'to what degree are employees in this (organization or country) paid on the basis of individual performance?' Hofstede, Neuijen, Ohayv and Sanders (1990) argued that national culture should be defined in terms of values, whereas organizational culture should be defined in terms of practices. By comparison, the GLOBE project (House et al., 2004) included both values based and practices based measures of national culture and organizational culture.

One can also distinguish measures according to the level of analysis or aggregation (Hanges \& Dickson, 2004; Trompenaars \& Hampden-Turner, 2000). For example, to measure national culture, Hofstede's (1980) items were, in conceptual terms, at the individual level. That is, each respondent was asked to describe his/her own values or work situation. However, Hofstede subsequently aggregated these individual level responses to the national level to obtain empirical measures of national culture dimensions. In contrast, in the GLOBE project (House et al., 2004), to measure national culture values (and also practices), respondents were not asked to report their own values or own work situation, but rather to describe the values of their society/country. As in Hofstede, these responses were then aggregated.

These different ways of conceptualizing and measuring national culture may yield different estimates of the country effect size. When the focus is on respondents' own work values (e.g., Hofstede, 1980, 2001), greater within-country variance in responses is expected (weakening the country effect size) than when the respondents are asked instead to describe their country (as in GLOBE). In the latter case, respondents may be more likely to report their view of what is average, typical, or even stereotypical of the nation (see Gerhart, 2008.) 
What is the difference between a country effect and a national culture effect? The effect size for country provides an upper bound on the effect size for national culture because, as noted in Figure 1, countries differ in ways other than national culture (Dowling, Festing, \& Engle, 2008). Thus, national culture effects can only be accurately estimated by using national culture scores rather than country dummy variables as a proxy (Schaeffer \& Riordan, 2003; Tsui et al., 2007). This has been framed as the question of whether national culture 'mediates' country effects (Kirkman, Lowe, \& Gibson, 2006), or, using the logic of hierarchical linear modeling (HLM) (Raudenbush \& Bryk, 2002) one can estimate the effect size for country and then the portion accounted for specifically by national culture means.

\section{EMPIRIGAL EVIDENGE ON COUNTRY AND NATIONAL GULTURE EFFECT SIZES}

The general hypothesis of interest is that national culture significantly constrains organizational culture (Hofstede, 1983, 2001; Johns, 2006). Having defined constraint in terms of variance restriction and culture in terms of shared variance and that which is unique, support for such a claim depends on the degree to which within-country variance is small relative to between-country variance (i.e., the effect size for country). Consistent with Figure 1, we would also like to know what portion of any country effect is due to a national culture effect.

Several types of empirical research are relevant here. First, evidence on the effect size of country on individual level cultural values would be informative, as the more variance there is at the individual level, the more likely there would be variance at the organization level (e.g., Au, 1999; Bloom \& Milkovich, 1999; Gelfand et al., 2006). Second, evidence on the effect size of country on organizational culture is useful in that it provides an upper bound on the national culture effect. Third, and most pertinent, is evidence on the effect size of national culture on organizational culture. I focus here on the second and third types of evidence. (For a review of the first type, see Gerhart \& Fang, 2005; Gerhart, 2008.) There is direct evidence of the second type available from two sources: Nelson and Gopalan (2003) and GLOBE (House et al., 2004). Direct evidence on the third question is not available, but it can be derived based on what was reported in the two published studies that I use to illustrate this issue.

\section{Nelson and Gopalan (2003)}

This study used 288 respondents from the USA, Brazil and India to measure organizational culture. Culture was defined for each country by the researchers on the basis of a review of the sociological and anthropological literatures (including Hofstede's 1980 work) on culture in the three countries, resulting in 16 
dimensions of cultural values representing four higher order dimensions: work (e.g., effort, time), relations (e.g., affect, sociability), control (e.g., dominance, status) and cognition (e.g., abstract thought, flexibility). An analysis of variance using country as the independent variable and each of the 16 cultural value dimensions as the dependent variables resulted in seven of the $16 F$-values being statistically significant. Additionally, I computed the mean variance explained by country across the 16 cultural values dimensions, which was one percent. ${ }^{[6]}$ Based on Cohen's benchmarks, this is a small effect size.

Nelson and Gopalan next performed a cluster analysis, which yielded five organizational culture clusters (or profiles) for India and four clusters for each the USA and Brazil. Next, they examined the clusters within each country to determine how many organizations had cultures that were isomorphic with their national cultures, as opposed to either rejective or ambiguous (meaning not clearly isomorphic or rejective). The number of isomorphic clusters in each country was as follows: 23 of 100 (India), 16 of 100 (USA) and 15 of 88 (Brazil). Thus, 59 (20.5 percent) of the 288 organizations had organizational cultures isomorphic with national culture, while the majority, 162, shared some values with the national culture but rejected others (i.e., ambiguous) and 67 clearly rejected/differed from the national culture. Thus, country influenced organizational culture in this study, but country did not constrain organizational culture to the degree that it prevented considerable variation in organizational culture.

The Nelson and Gopalan (2003) study did not provide information to allow estimation of a national culture (as opposed to country) effect. However, given that the country effect provides an upper bound on the national culture effect, we can infer that the national culture effect in their study, in terms of variance explained, would be less than one percent.

\section{GLOBE Study (House et al., 2004)}

The book, Culture, leadership, and organizations: The GLOBE study of 62 cultures (House et al., 2004) reports on the work of the GLOBE research program, which used a sample of 17,730 middle managers from 951 organizations in three industries (food processing, financial services, telecommunication services) in 62 countries. The GLOBE study represents a collaboration between 170 scholars from the 62 countries, and it studies culture in terms of both values (similar to Hofstede) and practices and does so at three levels of analysis (country, organization and individual). Here, we examine the GLOBE results using organizational culture means as the dependent variable. (For this analysis, GLOBE reported results only on practices, not on values). This is a very important set of results for evaluating the Javidan et al. (2004: 726) conclusion that 'organizations mirror societies from which they originate' when it comes to culture. 
As noted, it is important to avoid equating country effects with national culture effects. A major issue with the GLOBE research is that it does, in key instances, mistakenly imply that country effects are national culture effects. The title of Chapter 20, which reports empirical results, is 'Societal Culture and Industrial Sector Influences on Organizational Culture.' However, nowhere in Chapter 20 is the relationship between societal culture (i.e., national culture) and organizational culture examined. Rather, in actuality, Chapter 20 reports on the relationship between country (using country dummy variables) and organizational culture means.

Table 1 summarizes my re-analysis of the key findings from the GLOBE research on country (society). The country effect is estimated by GLOBE using an ANOVA with mean organizational culture as the dependent variable and socicty (i.e., country) dummy variables as the independent variables. The total effect of country is given in the $\mathrm{Eta}_{(\mathrm{C})}{ }^{2}$ column, which reports the average percentage of variance in organizational culture practice means that occurs at the country (society) level of analysis. ${ }^{[7]}$ Across the nine culture dimensions, the GLOBE researchers report that the mean variance explained by country is 23 percent, which, based on Cohen (1988), is a medium (bordering on large) effect size. This 23 percent is the upper bound for the effect of any specific characteristic of country such as national culture. (See Raudenbush \& Bryk, 2002: 74). $)^{[8]}$

To determine what part of this 23 percent effect of country is due to national culture, per se, it is necessary to consult the footnotes following Chapters 12 through 19 of the GLOBE book (House et al., 2004), ${ }^{[9]}$ which provide the information shown in the column, $R_{\text {coumtry, }}^{2}$ in Table $l$ of the present paper. We see that the $R^{2}$ between mean national culture and mean organizational culture is, on average, 27 percent. To estimate the percentage of total variance (i.e., not just variance at the country level) in organizational culture means that is explained specifically by differences in national culture means, we use the product, $E t a_{\text {org }}^{2}$ * $R_{\text {county }}^{2}$ (Raudenbush \& Bryk, 2002: 110). Across the nine culture dimensions, the mean is 6 percent, which, using Cohen's (1988) standards, is a small effect size. By implication, 94 percent of the variance in organizational culture scores is not explained by national culture (mean) scores. ${ }^{[10]}$ Also, the portion of the country effect due to a national culture effect is 27 percent, or roughly one-quarter of the total effect of country.

Does this finding mean that national culture is irrelevant for organizational culture? No. If one takes the square root of 6 percent, the result is 0.24 , which is comparable to the validity of some employee selection instruments and, in that context, would be described as moderate validity (Heneman, Heneman, \& Judge, 1997: chapter 12). Thus, national culture is meaningfully related to organizational culture, but not as strongly as has often been claimed and, arguably, not strongly enough for national culture to be a major constraint on organizational culture. 


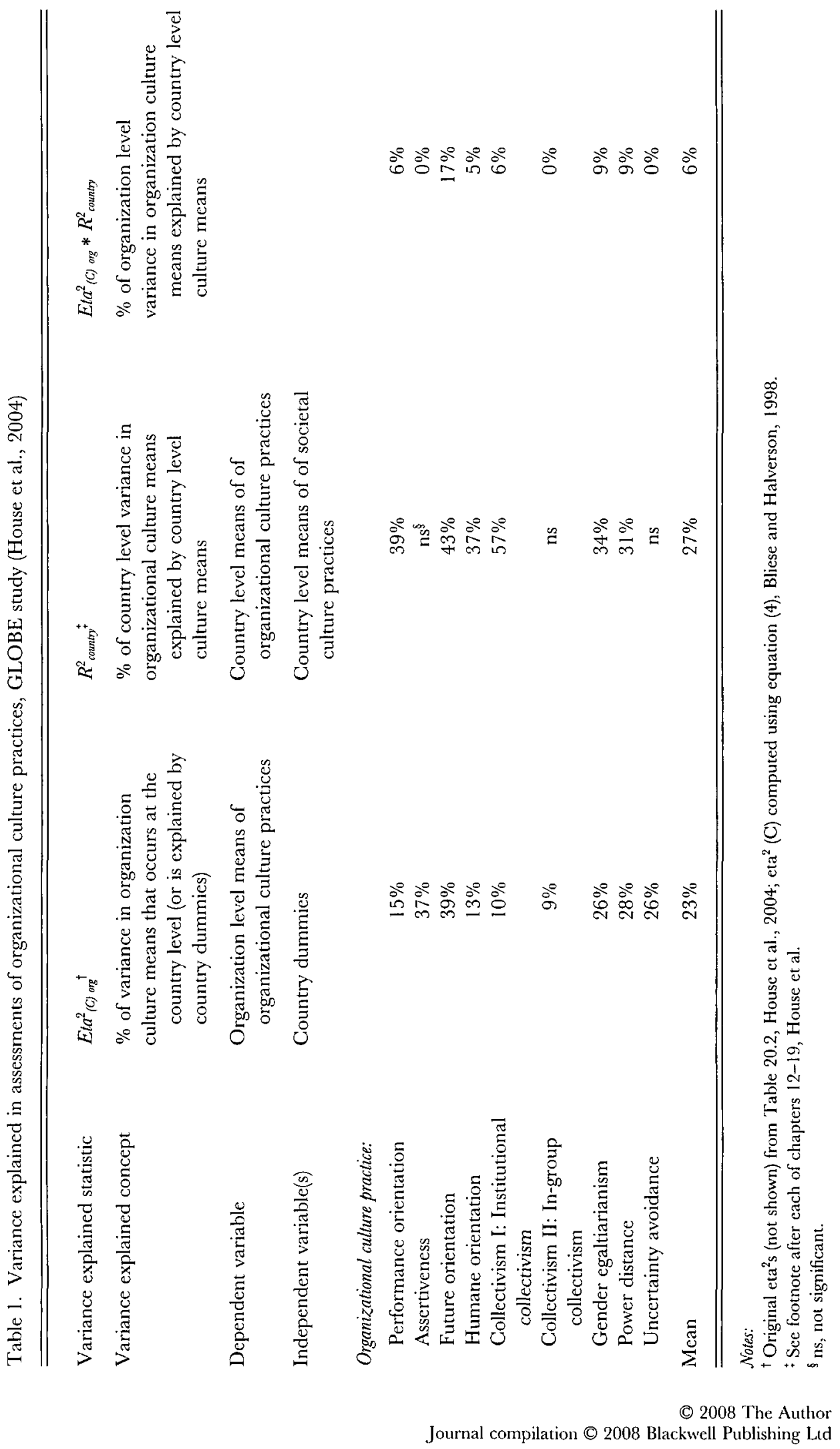




\section{DISCUSSION}

It has been argued that national culture constrains organizational culture (Hofstede, 1983, 2001), that national culture is a major component of the broader 'contextual imperative' that constrains organizational culture (Johns, 2006) and that organizational culture 'mirrors' national culture (GLOBE, Javidan et al., 2004). Although such claims fit with institutional theory, they are inconsistent with perspectives that emphasize management discretion and the central role of a unique organizational culture as a key path to sustained competitive advantage (e.g., the RBV, Barney, 1986, 1991). Such a path of differentiation is feasible only if organizations are not so strongly constrained by their environments that they are unable to significantly differentiate themselves. Thus, it is important to quantify the degree of potential constraint that contextual factors such as national culture potentially place on organizations.

Following Johns (2006) and others (Au, 1999; Nelson \& Gopalan, 2003), constraint was defined here in terms of observed restriction in variance. Specifically, to the extent that national culture acts as a constraint on organizational culture, we expect to see within-country variance in organizational culture to be restricted relative to between-country variance. This can be assessed by estimating the effect size for country on organizational culture. As a next step, the portion of the country effect that is due to a national culture effect can also be estimated.

In the Nelson and Gopalan (2003) study, less than one percent of the variance in organizational culture was explained by country. This one percent, in turn, represents an upper bound for any national culture effect. Using Cohen's (1988) benchmarks, one percent is the minimum for a small effect size. In the GLOBE research, country explained 23 percent of the variance in organizational culture. National culture, per se, explained 6 percent of the variance in organizational culture. These effect sizes are larger, but neither is 'large' using Cohen's benchmarks. As another way of framing the finding, 94 percent of the variance in organizational culture is not explained by national culture in the GLOBE research. In Nelson and Gopalan, 99 percent of the variance in organizational culture was unexplained.

These findings do not mean that national culture differences, or more broadly, country differences, are unimportant. What they do suggest, however, is that such differences may not be as strong as some have argued. Countries certainly do differ and such differences must be considered when designing and executing management strategies and practices and in setting organizational culture objectives. Further, differences between any two countries can be smaller or larger than what we have observed as the average differences in this study. Nevertheless, these facts do not mean that national differences necessarily act as a hard constraint or contextual imperative. Deciding to be unique, as long as the risks and challenges are fully understood and considered, is often possible and may offer the potential 
for competitive advantage. Thus, the room for discretion and differentiation should not be underestimated.

The model presented in Figure 1 seeks to understand when organizational culture would be less constrained by national culture (i.e., mean culture). A central hypothesis is that greater within-country variance in individual level cultural values will provide more room for the operation of managerial strategy and differentiation. If future researchers can obtain information on within-country variances by country, it would allow a test of the hypothesized role of intracultural variability as a possible moderator. Although the effect sizes I have summarized do not speak directly to this moderation (by intracultural variability) hypothesis, they do quantify, on average, the degree of within-country variance relative to between-country variance in individual and cultural level values. As noted, on average, withincountry variation is substantial, suggesting, on average, room for significant organizational differences.

\section{GONGLUSION}

The resource based view highlights the potential importance of differentiating organizational culture as a path to sustained competitive advantage. In contrast, the contextual view argues that organizational culture is largely determined by the environment, highlighting institutional forces such as national culture. My conceptual analysis and re-analysis of empirical evidence does not support the hypothesized strong role of national culture, on average, as a constraint on organizational culture. Therefore, organizations may have more discretion in choosing whether to localize or standardize organizational culture and related management practices than is suggested by conventional wisdom. Future research is needed to identify when national culture constrains organizational culture and when it is less likely to do so.

\section{NOTES}

[1] It is important to recognize, of course, that other factors, in addition to institutional pressures, may contribute to a divergence between planned and observed organizational culturc. For example, critical and unanticipated events during the history of the organization may create path dependence (Martin, 2002). More generally, the degree to which culture is something that is consciously created, shaped and managed versus the degree to which it is something that simply evolves has been debated (e.g., Barley, Meyer, \& Gash, 1988; Martin, 2002).

[2] An important issue here is level of analysis. Is organizational culture affected by both national culture and individual cultural values? Gclfand ct al. (2006: 1234) csscntially argue 'yes' and cmphasize the importance of 'bottom-up processes that relate psychological characteristics to organizational characteristics'. In their view, to the extent that individuals in a country share norms, these norms will also be seen in the organizational cultures within those countries. Similarly, Kostova and Roth (2002: 218-219) argue that 'institutional elements enter organizations through the people working in them ... [and] their cognitions and beliefs'. As noted earlier, Gerhart and Fang (2005) provide evidence that there is substantial within-country variance in individual cultural values. Au (1999) provides similar evidence. For a review and further discussion of this issue, see Gerhart (2008). 
[3] A constraint can also be defined as a statistical interaction. A particular type of organizational culture (or the human resource practices that are believed to play a role in determining that organizational culture) may have positive effects on performance in some environments (e.g., in some national cultures), but smaller or even negative effects in other environments. If, over time, firms either avoid using practices that are less effective in their environments and/or fail at a significantly higher rate when they fail to conform to environmental demands, the end result should be reduced variance in culture or practices, consistent with my definition of a constraint in terms of reduced variance.

[4] As Rosnow and Rosenthal (1989) demonstrate, practical significance depends on the area of study and even 'small' effects can be of practical significance.

[5] Culture scholars differ on the degree to which a quantitative approach to culture is meaningful (Martin, 2002). For example, as noted carlier in the treatment of the culture concept by Schein (1992) and in Barney (1986), culture is interesting in large part becausc it is so difficult to obscrve and describe. This property, however, also means that some scholars believe that culture can only be understood by becoming immersed in an organization (or nation). While acknowledging this issue, the fact remains that quantitative culture studies continue to be a major part of the culture literature, and it is thus important to understand what can be learned from them.

[6] Nelson and Gopalan reported an index of variance explained, but there appeared to be an error in its calculation for the effort dimension. Thus, I recomputed the variance explained for this dimension and then computed the average variance explained.

[7] These percentage variance explained numbers differ from those reported in GLOBE, Table 20.2, due to my use of equation (4) in Bliese and Halverson (1998) to correct for bias in $E t a^{2}$ resulting from small group size. The average group size used in GLOBE to generate these $E t a^{2} \mathrm{~s}$ is the number of organizations/number of societies, or $208 / 27=7.7$.)

[8] In the hierarchical lincar modeling (HLM) literature, the total societal (i.e., country) effect would be estimated from a random intercepts model, and then this total societal effect would be explained by specific societal characteristics such as culture in a means as outcomes model. Many HLM applications have two levels, where Level 1 is individuals and Level 2 is organizations. In that case, the first qucstion is how much variance among individual occurs at the organization level (random intercepts model), and the second question is how much of that organization level variance can be explained by specific organization characteristics (means as outcomes model). In contrast, the GLOBE model has three levels, where Level 3 is society. Thus, in the GLOBE study, a random intercepts model is used to determine how much of the variation among organizations (rather than among individuals) exists at the society level and then a means as outcomes model is used to determine how much of that society level variance can be explained by specific socicty level characteristics such as culture.

[9] After cach of the chapters (12-19), there is a foomote that includes the following statement: 'As reported in Chapter $20 \ldots$ we found that all the cultural dimensions of organizational cultural values and practices significantly differed across socictics. Although important, this prior analysis did not identify the particular aspect of societal differences that was related to organizational culture.' In other words, it is recognized after each chapter that Chapter 20 did not specifically examine the relationship between organizational culture and national culture.

[10] Readers may wonder whether the 6 percent estimate is biased upward because the same respondents provided organizational culture and national culture data. The answer is 'no' because the GLOBE study, consistent with the recommendation made by Ostroff, Kinicki and Clark (2002), was careful to use half of the respondents from cach organization to provide organizational culture scores and the other half to provide national culture scores (i.c., the split samplc approach).

\section{REFERENCES}

Au, K. Y. 1999. Intra-cultural variation: Evidence and implications for international business. Joumal of International Business Studies, 30(4): 799-812.

Bain, J. S. 1959. Industrial organization. New York: Wiley.

Barley, S. R., Meyer, G., \& Gash, D. 1988. Cultures of culture: Academics, practitioners, and the pragmatics of normative control. Administrative Science Quarterly, 33(1): 24-60.

Barney, J. B. 1986. Organizational culture: Can it be a source of sustained competitive advantage? Academy of Management Revieze, 11(3): 656-665. 
Barney, J. B. 1991. Firm resources and sustained competitive advantage.Joumal of Management, 17(1): 99-120.

Barney,J. B., \& Wright, P. M. 1998. On becoming a strategic partner: The role of human resources in gaining competitive advantage. Human Resource Management, 37(1): 31-46.

Bartlett, C. A., \& Ghoshal, S. 1989. Managing across borders: The transnational solution. Boston: Harvard Business School Press.

Becker, B., \& Gerhart, B. 1996. The impact of human resource management on organizational performance: Progress and prospects. Academy of Management Joumal, 39(4): 779-801.

Bliese, P. D., \& Halverson, R. R. 1998. Group size and measures of group-level properties: An cxamination of cta-squared and ICC values. Journal of Management, 24(2): 157-172.

Bloom, M., \& Milkovich, G. T. 1999. A SHRM perspective on international compensation and rewards. In P. M. Wright, L. Dyer, J. W. Boudreau, \& G. T. Milkovich (Eds.), Research in personnel and human resources management, (Suppl 4): 283-303. Stamford, CT: JAl Press.

Cappelli, P., \& Crocker-Hefter, A. 1996. Distinctive human resources are firms' core competencies. Organizational Dynamics, 24(3): 7-22.

Carmeli, A., \& Tishler, A. 2004. The relationships between intangible organizational elements and organizational performance. Strategic Management Journal, 25(13): 1257-1278.

Chatman, J. A., \& Jchn, K. A. 1994. Assessing the relationship between industry characteristics and organizational culture: How different can you be? Academy of Management Joumal, 37(3): $522-554$.

Cohcn, J. 1988. Statistical power analysis for the behavioral sciences (2nd ed.). Hillsdale, NJ: Lawrence Earlbaum Associates.

Cohcn, J. 1994. The earth is round (p<0.05). American Psychologist, 49(12): 997-1003.

Collins, J. 2001. Good to great: Why some companies make the leap . . and others don't. New York: Harper Business.

Deal, T. E., \& Kennedy, A. A. 1982. Corporate cultures: The rites and rituals of corporate life. Reading, MA: Addison-Weslcy.

Den Hartog, D. N., \& Verburg, R. M. 2004. High performance work systems, organizational culture and perceived organizational effectiveness. Human Resource Management Journal, 14(1): 55-78.

Denison, D. R. 1990. Corporate culture and organizational effectiveness. New York: Wiley.

DiMaggio, P. J., \& Powell, W. W. 1983. The iron cage revisited: Institutional isomorphism and collective rationality in organizational fields. American Sociology Revieze, 48(2): 147 160.

Dowling, P. J., Festing, M., \& Engle, A. D., Sr. 2008. International human resource management (5th ed.). London: Thomson Learning.

Gelfand, M. J., Nishii, L. H., \& Raver, J. L. 2006. On the nature and importance of cultural tightness-looseness. Journal of Applied Psychology, 91(6): 1225-1244.

Gerhart, B. 2008. National culture, intracultural variability, and attraction-selectionattrition. Working Paper, School of Business, University of Wisconsin-Madison.

Gerhart, B., \& Fang, M. 2005. National culture and human resource management: Assumptions and Evidence. International Joumal of Human Resource Management, 16(6): 975-990.

Hanges, P.J., \& Dickson, M. W. 2004. The development and validation of scales measuring societal culture and culturally-shared implicit theorics of leadership. In R. J. House, P. J. Hanges, M. Javidan, P. W. Dorfman, \& V. Gupta (Eds.), Culture, leadership, and organizations: The GLOBE study of 62 cultures: 122-151. Thousand Oaks, CA: Sage Publications.

Hannan, M. T., \& Freeman, J. 1977. The population ccology of organizations. American Joumal of Sociology, 82(5): 929-964.

Heneman, H. G., IlI, Heneman, R. L., \& Judge, T. A. 1997. Staffing organizations (2nd ed.). Chicago: Irwin.

Hofstede, G. 1980. Culture's consequences: International differences in zerk-related values. Beverly Hills, CA: Sage Publications.

Hofstede, G. 1983. The cultural relativity of organizational practices and theories. Journal of Intemational Business Studies, 14(2): 75-89.

Hofstcde, G. 2001. Culture's consequences: Comparing values, behaviors, institutions, and organizations across nations (2nd ed.). Thousand Oaks, CA: Sage Publications. 
Hofstede, G., Neuijen, B., Ohayv, D. D., \& Sanders, G. 1990. Measuring organizational cultures: A qualitative and quantitative study across twenty cases. Administrative Science Quarterly, 35(2): 286-316.

Hoopes, D. G., Madsen, T. L., \& Walker, G. 2003. Guest editors' introduction to the special issuc: Why is there a resource-based view? Toward a theory of competitive hetcrogencity. Strategic Management Journal, 24(10): 889-902.

Housc, R. J., Hanges, P.J., Javidan, M., Dorfman, P. W., \& Gupta, V. 2004. Culture, leadership, and organizations: The globe study of 62 societies. Thousand Oaks, CA: Sage Publications.

Javidan, M., Housc, R. J., Dorfman, P. W., Gupta, V., Hanges, P. J., \& de Luque, M. S. 2004. Conclusions and future directions. In R. J. House, P. J. Hanges, M. Javidan, P. W. Dorfman, \& V. Gupta (Eds.), Culture, leadership, and organizations: The GLOBE study of 62 cultures: 723-732. Thousand Oaks, CA: Sage Publications.

Johns, G. 2006. The essential impact of context on organizational behavior. Academy of Management Revieze, 31(2): 386-408.

Kerlinger, F. 1973. Foundations of behavioral research (2nd ed.). New York: Holt, Rinchart and Winston, Inc.

Kirkman, B. L., Lowe, K. B., \& Gibson, C. B. 2006. A quarter century of Culture's Consequences: A review of empirical research incorporating Hofstede's cultural values framework. Jourmal of International Business Studies, 37(3): 285-320.

Kochan, T. A., Katz, H. C., \& McKersie, R. B. 1994. The transformation of American industrial relations. New York: Basic Books.

Kostova, T., \& Roth, K. 2002. Adoption of organizational practice by subsidiaries of multinational corporations: Institutional and relational effects. Academy of Management Journal, 45(1): $215-233$

Kotter, J. P., \& Heskett, J. P. 1992. Corporate culture and performance. New York: Frec Press.

Krug, B., \& Hendrischke, H. 2008. Framing China: Transformation and institutional change through co-evolution. Management and Organization Review, 4(1): 81-108.

Lado, A. A., \& Wilson, M. C. 1994. Human resource systems and sustained competitive advantage: A competency-based perspective. Academy of Management Revieze, 19(4): 699-727.

Lawler, E. E. III. 2003. Treat people right! San Francisco: Jossey-Bass.

Martin, J. 2002. Organizational culture. London: Sage Publications.

Nelson, R., \& Gopalan, S. 2003. Do organizational cultures replicate national cultures? Isomorphism, rejection, and reciprocal opposition in the corporate values of three countries. Organization Studies, 24(7): 1115-1151.

Oliver, G. 1991. Strategic responses to institutional processes. Academy of Management Review, 16(1): 145-179.

Ostroff, C., Kinicki, A. J., \& Clark, M. A. 2002. Substantive and operational issues of response bias across levels of analysis: An example of climate-satisfaction relationships. Journal of Applied Psychology, 87(2): 355-368.

Oyserman, D., Coon, H. M., \& Kemmelmeier, M. 2002. Rethinking individualism and collectivism: Evaluation of theoretical assumptions and meta-analyses. Psychological Bulletin, 128(1): $3-72$.

Pelto, P. 1968. The difference between 'tight' and 'loose' societics. Transaction, 5(1): 37-40.

Perlmutter, H. V. 1969. The tortuous cvolution of the multinational corporation. Columbia Journal of World Business, 4(1): 9-18.

Peters, T. J., \& Watcrman, R. H. 1982. In search of excellence: Lessons from America's best-run companies. New York: Harper \& Row.

Porter, M. E. 1980. Competitive strategy. New York: Free Press.

Raudenbush, S. W., \& Bryk, A. S. 2002. Hierarchical linear models. Thousand Oaks, CA: Sage Publications.

Rosenzweig, P. M., \& Nohria, N. 1994. Influences on human resource management practices in multinational corporations. Journal of International Business Studies, 25(2): 229251.

Rosnow, R. L., \& Rosenthal, R. 1989. Statistical procedures and the justification of knowledge in psychological science. American Psychologist, 44(10): 1276-1284.

Schaeffer, B. S., \& Riordan, C. M. 2003. A review of cross-cultural methodologies for organizational research: A best-practices approach. Organizational Research Methods, 6(2): 169-215. 
Schein, E. H. 1992. Organizational culture and leadership (2nd ed.). San Francisco, CA: Jossey-Bass.

Schmidt, F. L. 1996. Statistical significance testing and cumulative knowledge in psychology: Implications for training of researchers. Psychological Methods, 1(2): 115-129.

Schneider, B. 1987. The people make the place. Personnel Psychology, 40(3): 437-453.

Scott, W. R. 2000. Institutions and organizations. Thousand Oaks, CA: Sage Publications.

Shrout, P. E., \& Fleiss, J. L. 1979. Intraclass correlations: Uses in assessing rater reliability. Psychological Bulletin, 86(2): 420-428.

Triandis, H. C. 1989. The self and social behavior in differing cultural context. Psychological Revieze, 96(3): 506-520.

Trompenaars, F., \& Hampden-Turner, C. 2000. Riding the waves of culture: Understanding cultural diversity in business (2nd ed.). London: Nicholas Breazley.

Tsui, A. S., Nifadkar, S. S., \& Ou, A. Y. 2007. Cross-national, Cross-cultural organizational behavior research: Advances, gaps, and recommendations. Journal of Management, 33(3): 426-478.

Tsui, A. S., Wang, H., \& Xin, K. R. 2006. Organizational culture in China: An analysis of culture dimensions and culture types. Management and Organization Revieze, 2(3): 345-376.

Wernerfelt, B. 1984. A resource-based view of the firm. Strategic Management Journal, 5(2): 171-180.

Barry Gerhart (bgerhart@bus.wisc.edu) is Professor of Management and Human Resources and the Bruce R. Ellig Distinguished Chair, School of Business, University of Wisconsin-Madison. He received his Ph.D. in Industrial Relations from the University of Wisconsin-Madison. His research interests include compensation, human resource strategy, international human resources, and employee movement.

Manuscript received: April 12, 2007

Final version accepted: May 22, 2008

Accepted by: Anne S. Tsui 